\title{
VIOLÊNCIA CONTRA A CRIANÇA, EDUCAÇÃO EM DiREITOS HUMANOS E JUSTIÇA CURRICULAR
}

\author{
Branca JuRema Ponce \\ Juliana FonseCA de Oliveira NerI \\ Pontifícia Universidade Católica de São Paulo (PUC-SP), São Paulo, \\ SP, Brasil
}

\begin{abstract}
RESUMO: Este artigo aborda as contribuições da Educação em Direitos Humanos na prevenção da violência contra a criança, destacando a centralidade daquela no processo formativo e evidenciando os compromissos da justiça curricular. Para tanto, vale-se de resultados parciais de uma pesquisa em andamento e de registros do eixo Educação Básica do Plano Estadual de Educação em Direitos Humanos - SP. A pesquisa aponta a necessidade de mais investimentos das instituições públicas e privadas em formações que promovam a reflexão e o exercício de construir relações humanas, assumindo uma postura ética diante da vida social, cultural e política em nível individual, coletivo e organizacional. Nesse sentido, a escola se apresenta como local de estruturação de consciência social e de constituição de sujeitos comprometidos com a promoção de direitos.
\end{abstract}

Palavras-chave: Educação em Direitos Humanos. Justiça curricular. Violência contra a criança. Escola na prevenção à violência.

INTRODUÇÃO

A concepção de criança como sujeito de direitos é historicamente recente na legislação brasileira. Ainda há muitos desafios a enfrentar na relação com a infância. Isso se mostra na convivência contraditória entre leis 
que protegem a infância e práticas sociais e relações humanas que ainda não a dignificam, naturalizando a violência em seus diversos tipos, muitas vezes com justificativas que desconsideram a fase peculiar de seu desenvolvimento, culpabilizando a criança pelos diversos tipos de violência que ela própria sofre, dando a castigos o caráter de ações "educativas". Para além dessas violências, as práticas institucionais e políticas públicas insuficientes para atuar no cuidado com as vítimas de violência aprofundam o sofrimento da vítima. É preciso que as instituições e as políticas públicas tenham fôlego para se voltarem ao encaminhamento e à prevenção de violências contra a criança.

A afirmação da dignidade humana da infância é urgente e necessária em todos os espaços sociais, instituições públicas e privadas, e faz-se por meio de um processo educativo que mobilize mentalidades e por práticas voltadas para os direitos humanos. Promover a Educação em Direitos Humanos (EDH) em todas as instituições, em espaços formais e não formais, contribui para disseminar em larga escala a cultura do respeito e o reconhecimento da humanidade em todas as crianças, questões fundamentais para a prevenção da violência. A Educação em Direitos Humanos é pensada para ser desenvolvida em diversas instituições, conforme descrito no Plano Nacional de Educação em Direitos Humanos - PNEDH:

O Estado brasileiro tem como princípio a afirmação dos direitos humanos como universais, indivisíveis e interdependentes e, para sua efetivação, todas as políticas públicas devem considerá-los na perspectiva da construção de uma sociedade baseada na promoção da igualdade de oportunidades e da equidade, no respeito à diversidade e na consolidação de uma cultura democrática e cidadã (BRASIL, 2009, p.11).

A escola, como instituição que alcança 94\% ${ }^{1}$ das crianças e dos adolescentes brasileiros no Ensino Fundamental e trabalha com eles por, no mínimo, 200 dias ou 800 horas no ano, tem papel de destaque na disseminação da Educação em Direitos Humanos: com os educandos, com os profissionais envolvidos com a escola e com toda a comunidade do seu entorno.

A escola é reconhecida por especialistas como local de estruturação de concepções de mundo, de possível construção de consciência social, de circulação e de consolidação de valores, de promoção da diversidade cultural, de formação para a cidadania e de constituição de sujeitos sociais. Por meio do processo de reconhecimento da pluralidade e de valorização da alteridade, exercitando a criticidade no debate de ideias para o reconhecimento e o respeito a todos e a cada um, com especial atenção aos historicamente excluídos e discriminados, formam-se sujeitos responsáveis e capazes de 
ações de promoção e defesa de direitos, seja na reparação de violações em qualquer espaço social, seja no encaminhamento de ações preventivas.

O currículo escolar no exercício da justiça curricular não pode prescindir desse processo formativo. Antes, tem o dever de dar centralidade a essa formação da Educação em Direitos Humanos (EDH).

Este artigo aborda inicialmente o conceito de Educação em Direitos Humanos. Inspirado na teoria crítica da Escola de Frankfurt enfatiza a reflexão sobre para quem, por que e para que deve-se investir na Educação em Direitos Humanos, perpassando também os conceitos de violência e dignidade humana que tangenciam a EDH, de acordo com as referências do Programa Mundial de Educação em Direitos Humanos e dos Planos Nacional e Estadual - SP de EDH.

Em seguida, destaca a importância do envolvimento de instituições e atores sociais que lidam de forma direta ou indireta com a criança na afirmação e no fortalecimento da centralidade da EDH no processo formativo dos trabalhadores e no planejamento de ações.

Por fim, apresenta a prevenção da violência contra a criança por meio da EDH na escola como tema central no exercício da justiça curricular, na medida em que visa à afirmação da criança como sujeito de direitos e à possibilidade da ação cidadã desde a infância. Por meio da construção de conhecimentos, da disseminação de possibilidades de autoproteção, da participação na elaboração de políticas públicas voltadas para o tema e de ações de prevenção, esse caminho pode ser viabilizado.

\section{Para quem, por que e para que uma Educação em Direitos Humanos $(\mathrm{EDH})$}

A Educação em Direitos Humanos vem sendo caracterizada como um processo sistemático e multidimensional orientado à formação do sujeito de direitos, da cidadania ativa e participante de caráter democrático. Articula diferentes atividades que desenvolvem conhecimentos, atitudes, sentimentos e práticas sociais que afirmam uma cultura de direitos humanos na escola e na sociedade, por meio de processos de desenvolvimento da consciência da dignidade humana de cada pessoa no nível pessoal e social, ético e político, cognitivo e celebrativo. Utiliza metodologias participativas e de construção coletiva que empregam a pluralidade de linguagens e materiais de apoio (superando estratégias pedagógicas meramente expositivas), visando à orientação e a mudanças de mentalidade, a atitudes e práticas individuais e coletivas (CANDAU, 1998). 
Dignidade humana não é algo que se adquire, é inerente aos humanos. Maria Victoria Benevides define:

[...] dignidade é a qualidade própria da espécie humana que confere a todos e a cada um o direito à realização plena como ser. [...] é aquele valor - sem preço! - que está encarnado em todo ser humano. Direito que Ihe confere o direito ao respeito e à segurança - contra a opressão, o medo, e a necessidade - com todas as exigências que, na atual etapa da humanidade, são cruciais para a sua constante humanização (BENEVIDES, 2005, p. 12).

Observe-se que a EDH se volta para todos e cada um, incluindo a criança. Não há recorte etário, geracional, para a vivência desse princípio. Portanto, não há restrições para que todos e cada um se realizem plenamente como seres humanos.

Essa ideia converge com o "pleno desenvolvimento" preconizado pela LDB (artigo $2^{\circ}$ ), como também com a concepção freiriana de ser mais (ZITKOSKI, 2010, p. 369-371). Freire afirma o princípio da dignidade humana e sua plena realização com a expressão ser mais, como desafio da libertação dos oprimidos, como busca de humanização. Esta é uma contribuição da EDH na prevenção da violência contra a criança. Conceber a criança como sujeito, reconhecer sua dignidade humana e suas possibilidades de ser mais são práticas que se contrapõem às de violência.

Etimologicamente, a palavra violência vem do latim vis, força, e significa: 1) tudo o que age usando a força para ir contra a natureza de algum ser (é desnaturar); 2) todo ato de força contra a espontaneidade, a vontade e a liberdade de alguém (é coagir, constranger, torturar, brutalizar); 3 ) todo ato de violação da natureza de alguém ou de alguma coisa valorizada positivamente por uma sociedade (é violar); 4) todo ato de transgressão contra aquelas coisas e ações que alguém ou uma sociedade define como justas e como um direito; 5) consequentemente, a violência é um ato de brutalidade, sevícia e abuso físico e/ou psíquico contra alguém e caracteriza relações intersubjetivas e sociais definidas pela opressão, intimidação, pelo medo e pelo terror.

A violência se opõe à ética porque trata seres racionais e sensíveis, dotados de linguagem e de liberdade, como se fossem coisas, isto é, irracionais, insensíveis, mudos, inertes ou passivos. Na medida em que a ética é inseparável da figura do sujeito racional, voluntário, livre e responsável, tratálo como se fosse desprovido de razão, vontade, liberdade e responsabilidade é tratá-lo não como humano e sim como coisa, fazendo-lhe violência nos cinco sentidos que demos a esta palavra (CHAUÍ, 2006, p. 341-342). 
A EDH precisa ser realizada e enraizada para que as relações humanas sejam de fato humanizadoras, contribuam para o desenvolvimento das possibilidades de criar, transformar, buscar ser em relação, sem o uso da força, sem estar contra a natureza racional e sensível do semelhante. Em episódios de violência contra a criança, essas possibilidades humanas são feridas.

No contexto de um deslocamento do ser humano do centro para a periferia das políticas e práticas sociais, é ainda mais necessário afirmar a importância da EDH como central na formação humana. Esse deslocamento, após o golpe político-parlamentar-midiático-jurídico de 2016, tem sido mais ameaçador: 1) na medida em que forças conservadoras, autoritárias, fundamentalistas e reacionárias ganham força; 2) na medida da assunção pelas políticas públicas de valores emanados pelo mercado que têm gerado políticas despreocupadas com a vida, que, por sua vez, geram perdas de direitos trabalhistas, de segurança, do direito à saúde e da educação pública de qualidade; 3) na medida da naturalização e da banalização da violência, principalmente quando esta se destina às chamadas minorias (que quantitativamente são, muitas vezes, maiorias). Nesse contexto, é fundamental que os seres humanos enraízem em si mesmos e na sociedade relações e práticas sociais (em sua relação sustentável com o meio ambiente) que envolvam a cultura de direitos, de modo especial, de direitos humanos.

Zenaide (1994) aponta que educar em direitos humanos demanda que o processo pedagógico esteja embasado em objetivos claros de promoção e socialização de uma cultura em direitos humanos que rompa com a naturalidade e a normalidade das violações, o que requer intervenções sistemáticas na formação de valores, hábitos e atitudes que fortaleçam a dignidade, o pluralismo, a democracia, o respeito à diversidade sociocultural. Tais práticas devem prever o incentivo à convivência e a relações de solidariedade na formação de sujeitos que exercitem ativamente uma cidadania democrática, transformadora.

Isso foi também previsto no Programa Mundial de Educação em Direitos Humanos - PMEDH. Lê-se em seu plano de ação:

São objetivos balizadores do PMEDH conforme estabelecido no artigo 20: a) fortalecer o respeito aos direitos humanos e liberdades fundamentais; b) promover o pleno desenvolvimento da personalidade e dignidade humana; c) fomentar o entendimento, a tolerância, a igualdade de gênero e a amizade entre as nações, os povos indígenas e grupos raciais, nacionais, étnicos, religiosos, linguísticos; d) estimular a participação efetiva das pessoas em uma sociedade livre e democrática governada pelo Estado de Direito; e) construir, promover e manter a paz (ONU,1997, apud BRASIL, 2009, p. 24). 
Assim como afirmado por Zenaide (1994) e no PMEDH, as intervenções sistemáticas na formação que fortaleça a dignidade foram também contempladas no Plano Nacional de Educação em Direitos Humanos, conforme pode ser observado nos seus objetivos gerais:

São objetivos gerais o PNEDH: [...] b) enfatizar o papel dos direitos humanos na construção de uma sociedade justa, equitativa e democrática; c) encorajar o desenvolvimento de ações de educação em direitos humanos pelo poder público e a sociedade civil por meio de ações conjuntas[...] h) orientar políticas educacionais direcionadas para a constituição de uma cultura de direitos humanos (BRASIL, 2009, p.26-27).

Com base nessas referências, o Plano Estadual de Educação em Direitos Humanos de São Paulo também enfatizou:

A construção do Plano Estadual de Educação em Direitos Humanos para o estado de São Paulo vem como demanda histórica do movimento social organizado que há décadas luta por uma cultura de direitos humanos, que parte do reconhecimento da dignidade de cada pessoa, de sua singularidade, em que há projetos comuns dentro de suas particularidades de identidades, sociais, culturais, étnicas, geracionais, de gênero e orientação sexual (SÃO PAULO, 2017, p. 8).

Apesar da caracterização de EDH de Zenaide (1994) e Candau (1998), bem como o PMEDH, PNEDH e PEEDH-SP aqui retomados, ainda há muitos desafios na prática da EDH para que se enraíze uma cultura de direitos humanos. Ela é recente na sociedade brasileira, que foi historicamente marcada por um longo período de escravidão, regimes autoritários e práticas antidemocráticas (SILVA, 2010), visíveis nos ranços que dificultam que as pessoas conheçam e reconheçam seus direitos (principalmente as crianças e os adolescentes) e que se entendam como sujeitos históricos implicados nas consequências de seus atos e omissões. Nesse cenário de necessidade de avanços culturais na compreensão de que o ser humano deve estar no centro de toda preocupação e de que a criança é sujeito histórico e de direitos, a promoção dos direitos humanos é urgente e necessária em todas as instituições e, portanto, na escola. É disso que tratam os tópicos que seguem. 


\section{A NECESSIDADE DA EDH EM DIVERSOS SETORES PARA A PREVENÇÃo DA VIOLÊNCIA CONTRA A CRIANÇA}

Não há tantas brechas para a violência contra a criança quando há uma cultura de respeito ao outro (de qualquer idade, raça, gênero, etc.) que se impõe, quando há reconhecimento da dignidade humana. Há que se garantir que haja o maior número possível de pessoas e instituições que tenham um olhar sensível para detectar sinais de violência contra a criança e possam agir com encaminhamentos adequados, visando à prevenção, à autoproteção da criança, bem como a seu cuidado integral, biopsicossocial. Em casos de suspeita ou confirmação de que a criança esteja sendo vítima, é preciso que o cuidado seja prioridade anterior à criminalização do agressor.

O envolvimento de diversas instituições e também da sociedade civil no cuidado integral com a criança, efetivando que esta é prioridade absoluta do Estado, conforme preconiza o ECA, é imprescindível para que a EDH se constitua como política de Estado, permeando as políticas públicas dos mais diversos setores.

Cabe destacar a importante participação da sociedade civil organizada, co-autora e parceira na realização dos objetivos do PNEDH. De fato, a efetivação dos compromissos nele contidos somente será possível com ampla união de esforços em prol da realização dessa política, a qual deve se configurar como política de Estado (BRASIL, 2009, p.12).

São objetivos do PNEDH:

[...] f) propor a transversalidade da educação em direitos humanos nas políticas públicas, estimulando o desenvolvimento institucional e interinstitucional das ações previstas no PNEDH nos mais diversos setores (educação, saúde, comunicação, cultura, segurança e justiça, esporte e lazer, dentre outros) (p. 26).

Pesquisas recentes apontam que o problema da violência contra a criança permanece ocorrendo, na maioria das vezes, em âmbito doméstico (FONSECA et al., 2012) e que, apesar dos números alarmantes de denúncias de violência negligencial, física, psicológica, química e sexual, esses casos ainda são apenas a ponta visível do iceberg. O silêncio e a invisibilidade do problema ainda são os principais entraves para a dificuldade de romper um ciclo tão antigo de descaso e crueldade com a infância, que revela a negação de seus direitos fundamentais de se desenvolver plenamente nessa fase peculiar da vida. 
Guerra conceitua a Violência Doméstica contra a Criança e o Adolescente (VDCA), destacando que ela representa

[...] todo ato de omissão, praticado por pais, parentes ou responsáveis, contra crianças e/ou adolescentes que - sendo capaz de causar dano físico, sexual e/ou psicológico à vítima - implica, de um lado, uma transgressão do poder/ dever de proteção do adulto e, de outro, uma coisificação da infância, isto é, uma negação do direito que crianças e adolescentes têm de ser tratados como sujeitos e pessoas em condição peculiar de desenvolvimento (GUERRA, 1998, p. 32-33).

Ainda que a abordagem de dados quantitativos relacionados à violência doméstica contra a criança esteja envolta em imprecisões devido aos tabus que dificultam a denúncia e a notificação desses casos (conforme evidenciado em pesquisas nas áreas de saúde, educação, psicologia, serviço social, dentre outras), dados epidemiológicos indicam altos índices de maustratos (ZANATTA; DELL'AGLIO; CASTELLÁ, 2016) e reafirmam que estes ainda ocorrem de forma velada, dificultando ações de proteção. Por isso, prevenir a violência contra a criança implica agir para o fortalecimento dos direitos humanos em todos os espaços, a fim de que as instituições e atores sociais tenham um olhar sensível para conseguir identificar os sinais de suspeita do problema e atuar de forma protetiva com relação à criança.

Definido o conceito de violência doméstica contra a criança, ainda é necessário aprofundar a reflexão sobre a prevenção. $\mathrm{O}$ artigo 70 do ECA preconiza que é dever de todos prevenir a ocorrência de ameaça ou violação dos direitos da criança e do adolescente, o que reforça a tese aqui defendida de envolvimento de todas as instituições, serviços e sujeitos na prevenção.

A palavra prevenir vem do latim praevenire, "antecipar, perceber previamente", literalmente "chegar antes", de prae-, "antes", mais venire, "vir". Para prevenir ou "chegar antes" que algo indesejável aconteça com a criança e poder tomar medidas necessárias, é preciso sensibilidade, saber perceber os sinais de que a criança pode estar sendo vítima de violência. Para isso, os adultos do entorno da criança, das instituições que ela frequenta (escola, posto de saúde, instituições religiosas, instituições culturais, etc.), precisam ter sido formados para tal. Na formação específica para saber detectar sinais de violência, é necessário incluir a formação de base que concebe a criança como sujeito, como pessoa em condição peculiar de desenvolvimento, conforme preconiza a Declaração Universal dos Direitos Humanos, no artigo 10: "todos os seres humanos nascem livres e iguais em dignidade e direitos".

Para conseguir detectar os sinais e encaminhar o caso suspeito para que a rede de proteção social possa cuidar da criança e de sua família de forma 
adequada, evitando-se agravo ou reincidência da violência, é necessário ainda que todos os sujeitos sociais e instituições tenham sido sensibilizados pelo processo formativo de Educação em Direitos Humanos, o que está previsto desde o Plano Nacional de Educação em Direitos Humanos, que destaca a necessidade do reconhecimento do princípio normativo da dignidade humana (BRASIL, 2009, p.23), as dimensões de afirmação de valores, atitudes e práticas sociais que expressem a cultura dos direitos humanos em todos os espaços da sociedade e a importância da formação de uma consciência cidadã capaz de se fazer presente em níveis cognitivo, social, ético e político (BRASIL, 2009, p. 25).

Ao contrário dessa desejada Educação em Direitos Humanos, a grande mídia, uma das principais formadoras de mentalidades na atual sociedade brasileira, tem abordado o problema da violência contra a criança de maneira que pouco contribui para a prevenção. Canais de TV aberta, jornais e revistas impressos de grande circulação têm pautado o tema de forma sensacionalista, com caráter de espetacularização, o que gera audiência e lucro. A polarização e a falta de embasamento, a baixa qualidade na abordagem da temática impedem o olhar para a complexidade e a multicausalidade do problema. Criam-se "monstros prontos para o linchamento em praça pública". Omitem a violência estrutural histórica de nossa sociedade, a impossibilidade de acesso a direitos sociais por famílias inteiras, as questões culturais na forma de ver e lidar com a infância, a reprodução da agressão por quem já foi agredido. Por fim, não oferecem alternativas de educação não violenta, assim como não dão a conhecer os avanços revelados na literatura acadêmica como alternativas mais eficazes na redução do problema.

Estudos sobre prevenção da violência contra a criança dos últimos dez anos ${ }^{2}$ apresentam interfaces com diferentes espaços sociais, instituições públicas e privadas. $O$ resultado da pesquisa na literatura recente revelou a realização de trabalhos nas áreas de enfermagem, saúde coletiva, psicoterapias analíticas grupais, saúde materno-infantil, psicologia do desenvolvimento, serviço social, educação, dentre outras, reafirmando a característica multicausal do problema e a atuação interdisciplinar na sua prevenção e no seu enfrentamento.

Destacam-se dentre esses trabalhos: a atuação na prevenção por meio de consultas, visitas domiciliares, atividades grupais, parcerias com escolas e professores em eventos festivos, auxiliando na desnaturalização e na desconstrução social do problema (DE OLIVEIRA et al., 2013); o processo de produção e seleção de indicadores para avaliar ou monitorar estratégias de prevenção de violência e promoção de relações familiares e comunitárias 
protetoras (DESLANDES et al., 2010); a articulação das práticas profissionais para o enfrentamento e a prevenção do problema (ALBUQUERQUE et al., 2015); o olhar atento para as características que levam à reincidência, ao agravamento e à evolução dos casos (FONSECA et al., 2012); a importância da identificação da chamada "população de risco", estabelecendo um conjunto de ações articuladas em rede para oferecer proteção e apoio às famílias, além de estratégias para prevenção e enfrentamento, garantindo, dessa forma, a proteção e a defesa dos direitos da criança e do adolescente (BUENO, 2015); a descrição de mecanismos envolvidos na transmissão geracional da violência, oferecendo pistas para a prevenção (BÉRGAMO; BAZON, 2011); os desafios para a notificação (ZANATTA; DELL'AGLIO; CASTELLÁ, 2016; DE OLIVEIRA et al., 2013).

Mesmo diante de tantas possibilidades de contribuição, a escola tem envolvimento essencial na prevenção e no enfrentamento da violência contra a criança. Como espaço de socialização secundária, se a maioria das violências ocorre em âmbito doméstico (socialização primária), é na escola que o problema aparece ao impactar a aprendizagem, as relações e o pleno desenvolvimento do educando, além de ser a escola a única possibilidade, na maioria das vezes, para a criança deixar transparecer seu sofrimento e pedir ajuda. É disso que trata o tópico a seguir.

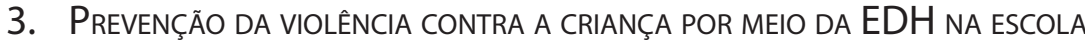

Na escola, o problema da violência contra a criança tem aparecido de forma mais explícita. Com a universalização do acesso e os compromissos dos planos de educação com a permanência do educando, o problema não pode mais ser escamoteado. Num tempo histórico recente, o sistema escolar tinha mecanismos que expulsavam a criança vítima de violência da escola, na medida em que esta apresentava (na maioria das vezes) alterações no comportamento, dificuldades de aprendizagem e de relacionamento interpessoal. Com a busca pela permanência, os problemas "de fora" afetam a escola cada vez mais e ela precisa se adaptar, se formar para saber lidar com os problemas que adentram seus muros, procurando não deixar que essas questões emergentes prejudiquem o processo de escolarização da criança. Por essa razão, defende-se mais uma vez a urgência de que a escola aborde centralmente a Educação em Direitos Humanos no seu currículo.

Para Saul (2010, p.109), cuja afirmação é pautada na concepção freiriana de educação, currículo é a política, a teoria, a prática do que-fazer na educação, no espaço escolar, e nas ações que acontecem fora desse espaço, numa perspectiva crítico-transformadora. Portanto, defender a centralidade 
da EDH no currículo presume opções políticas em todos os espaços e ações que acontecem dentro e fora da escola, numa perspectiva de compreender os processos e contextos históricos que geram opressões para ter elementos que embasem o planejamento e as ações de transformação dessas opressões.

Os planos de Educação em Direitos Humanos afirmam-se nessa perspectiva de transversalidade, de interdisciplinaridade. Para dar sua contribuição à construção da justiça social, o currículo escolar, responsável pela formação dos sujeitos, deve se posicionar de forma favorável às parcelas mais fragilizadas da população, deve estar comprometido em desnaturalizar, em tirar a legitimidade, em desvelar os processos de opressão.

A pesquisa em curso tem apontado várias dificuldades da escola para lidar com o problema da violência contra a criança. Um dos entraves que permeiam algumas dessas dificuldades evidenciadas é colocar a vítima num lugar de inércia, desconsiderando sua capacidade de autoproteção (se forem desenvolvidos conhecimentos e vínculos para isso), e de resistência e luta (conhecer formas e locais para fazer a denúncia e fortalecer a articulação da rede de proteção para que esta atue nos cuidados necessários para conseguir reduzir os danos provocados pelaVDCA). Chauí (2006) aponta uma concepção de vítima que auxilia na reflexão sobre a questão:

[...] o sujeito ético ou o sujeito de direito está cindido em dois: de um lado, o sujeito como vítima, como sofredor passivo e, de outro lado, o sujeito ético piedoso e compassivo que identifica o sofrimento e age para afastá-lo. Isso significa que a vitimização faz com que o agir ou a ação fiquem concentrados nas mãos dos não-sofredores, das não-vítimas, que devem trazer, de fora, a justiça para os injustiçados. Estes, portanto, perderam a condição de sujeitos éticos propriamente ditos para se tornar objetos de nossa compaixão. Isso significa que, para que os não-sofredores possam ser éticos, são necessárias duas violências: a primeira, factual, é a existência de vítimas; a segunda, o tratamento do outro como vítima sofredora passiva e inerte (CHAUÍ, 2006, p. 344).

Ao contrário dessa visão, mostra-se como alternativa de prevenção afirmar a criança como sujeito histórico que pode exercitar a sua cidadania, o seu direito à participação desde a infância na escola. Para isso, é preciso exercer a justiça curricular, evidenciando sua dimensão de convivência democrática (PONCE; NERI, 2015), proporcionando espaços participativos nos quais os educandos tenham assegurado o seu direito de criticar, além de ações voltadas para a elaboração de proposituras e alternativas para a transformação de realidades opressoras. 
O Plano Nacional de Enfrentamento à Violência Sexual contra Crianças e Adolescentes (BRASIL, 2013) caminha nessa direção, ao apresentar um eixo que denomina Protagonismo Infantojuvenil. O eixo se propõe a promover a participação ativa de crianças e adolescentes na defesa e na execução de políticas de proteção de seus direitos (p. 9). Tem como diretriz o fomento de estratégias e mecanismos que facilitem a participação organizada e a expressão livre de crianças e adolescentes sobre assuntos a eles relacionados, considerando sua condição peculiar de desenvolvimento (p. 17). Os objetivos estratégicos do plano visam promover o protagonismo e a participação de crianças e adolescentes nos espaços de convivência e de construção da cidadania, inclusive nos processos de formulação, deliberação, monitoramento e avaliação das políticas públicas, por meio de escuta nos serviços de atenção e em todo processo judicial e administrativo que os envolva, bem como a ampliação do acesso de crianças e adolescentes aos meios de comunicação para a expressão e a manifestação de suas opiniões (p.17). Esses objetivos previstos no plano se tornam mais efetivos, factíveis, quando a criança já tem o hábito de participar, quando já vivencia a forma democrática de organização, planejamento e monitoramento de ações na escola.

O currículo escolar preocupado com a prevenção da violência e com a autonomia da criança ocupa-se com o exercício da cidadania desde a infância, com a qualificação do seu aprendizado no processo de participação, com a dimensão da convivência democrática.

Participar é fazer-se presente na tomada de decisões sobre os rumos da sociedade (FREIRE, 1983, p.37), numa renúncia a ser simplesmente espectador (p. 66), e implica um "estar presente na História e não simplesmente nela estar representada" (FREIRE, 2001, p.75).

O papel da escola em desenvolver a criança como um sujeito histórico contribui para a possibilidade de emancipação das opressões que sofre. Segundo Gadotti (2012),

A palavra "emancipar" vem de ex-manus ou de ex-mancipium. Ex (indica a ideia de "saída" ou de "retirada") e manus ("mão", simbolizando poder). Emancipar seria então "retirar a mão que agarra", "libertar, abrir mão de poderes", significa "pôr fora de tutela". Ex-manus (fora- mão) significa "pôr fora do alcance da mão". Emancipar-se é, então, dizer a quem nos oprime: "tire a sua mão de cima de mim!". Emancipar-se é, então, conquistar liberdade, autonomia, independência, não apenas política, mas também econômica. Não pode estar emancipado aquele que passa fome, que não tem um teto, que não tem o que vestir (GADOTTI, 2012, p.1). 
Numa perspectiva de educação emancipatória, o currículo escolar se compromete com uma visão de mundo transformadora, inconformada com as injustiças e violências do mundo em que vivemos, proporcionando processos participativos em que a criança atue na prevenção das violências. A EDH torna-se central nessa compreensão de currículo na medida em que este se dedica ao desenvolvimento do pensamento crítico do educando, com base na afirmação permanente da dignidade humana em todo o espaço, todas as decisões e todas as ações escolares.

Práticas que ajudem o educando a compreender seu contexto e a julgar a si próprios como pessoas éticas, solidárias, colaborativas e corresponsáveis por um projeto de intervenção sociopolítica destinado a construir um mundo mais humano, justo e democrático (TORRES SANTOMÉ, 2013 , p. 9) são premissas que vêm sendo reafirmadas no conceito de justiça curricular.

Processos educativos que considerem a EDH no currículo visando à prevenção das violências contemplam o caminho à justiça curricular também no que tange a construção de conhecimentos vivos que afirmem os contextos de vida do educando, garantindo-lhe uma visão crítica do mundo e o acesso aos bens culturais como parte do seu pleno desenvolvimento (PONCE; NERI, 2017). Para que o currículo se comprometa com o desenvolvimento integral do educando, o contexto de vida não pode estar de fora dele, precisa ser colocado em pauta para estudo e intervenção dos educandos, para que estes se formem como seres humanos sensíveis às questões que os oprimem e/ou oprimem as parcelas mais fragilizadas da população.

Para Souza e Oliveira (2017),

[...] é possível inclusive dizer que para ser protagonista na construção da justiça social, a escola precisa tomar partido! Enquanto instituição social responsável pela formação de indivíduos, a escola deve se posicionar sempre ao lado do bem coletivo, social, comunitário. A escola deve tomar um posicionamento favorável à(s) parcela(s) mais fragilizada(s) da população. Nas palavras de Paulo Freire (2005), a escola deve estar ao lado do oprimido, contra o opressor, no intuito de tirar a legitimidade do processo de opressão. O conceito de opressão aqui pode ser entendido em diversas dimensões, entre as quais destaca-se não só a dimensão econômica e social, mas também a política, a cultural e a ideológica (SOUZA; OLIVEIRA, 2017, p.128).

A partir dos compromissos da justiça curricular, do currículo escolar que se queira emancipatório e inserido numa perspectiva críticotransformadora de educação, favorável às questões que oprimem as parcelas mais fragilizadas da população (como as crianças vítimas de violência), a centralidade da EDH é necessária e urgente. 


\section{Conclusões}

No momento de construção de uma outra história possível, é preciso lidar com as resistências, afirmar a coerência do discurso com a prática, afirmar intensamente o diálogo sempre articulando a promoção e a defesa dos direitos humanos, sem perder a capacidade de se indignar, de sentir a dor do outro e identificar-se com ela, mantendo a amorosidade e a esperança. Esperança ativa, sem espera, que dá continuidade a práticas iniciadas na luta inesgotável por uma ordem social mais justa e livre.

A escola, toda a comunidade e a rede de proteção social precisam estar envolvidas em ações em nome da proteção, da promoção e da defesa dos direitos, para que saibam identificar situações de desrespeito à dignidade da pessoa humana e aos direitos humanos. Dada nossa herança histórica, é necessário um investimento maior na formação das instituições públicas e privadas, de trabalhadores, de educandos e comunidades para que reflitam e se exercitem na humanização das relações, aprendendo a assumir posturas éticas na vida social, cultural e política em nível individual, coletivo e organizacional.

Se a intenção é formar seres humanos cujas ações se voltem para o coletivo, para o bem comum, a escola, como principal instituição formativa de crianças, precisa atuar e educar de forma democrática, para desenvolver uma cidadania ativa voltada para a participação do cidadão na vida pública, na promoção e na defesa dos direitos de todos, com especial atenção às parcelas fragilizadas da população (como as crianças vítimas de violência).

Que sejam desencadeadas ações de promoção e defesa dos direitos, bem como a reparação das violações, em todos os espaços sociais. Que se enraíze uma cultura de direitos humanos e que as políticas públicas elevem a EDH à política de Estado por um projeto de nação voltado para a dignidade humana. 
VIOLENCE AGAINST CHILDREN, EDUCATION IN HUMAN RIGHTS AND CURRICULAR JUSTICE

ABSTRACT: This article addresses the contributions of Human Rights Education in the prevention of violence against children. It emphasizes the centrality of this in the formative process. It focuses on the commitments of curricular justice. It uses partial results of an ongoing research and records of the Basic Education axis of the State Plan of Education in Human Rights - SP. It suggests more investments of public and private institutions in formations that promote the reflection and the exercise of constructing human relations, assuming an ethical attitude towards social, cultural and political life at the individual, collective and organizational levels. It highlights the school as a place for structuring social awareness and for the constitution of subjects committed to the promotion of rights.

KEYWORDS: Human Rights Education. Curricular Justice.Violence against children.School in the prevention of violence.

\section{VIOLENCIA CONTRA EL NIÑO, EDUCACIÓN EN DERECHOS HUMANOS Y JUSTICIA CURRICULAR}

RESUMEN: Este artículo se ocupa de las contribuciones de la Educación en Derechos Humanos en la prevención de la violencia contra el niño, destacando su centralidad en el proceso formativo y mostrando los compromisos de la justicia curricular. Para eso, utiliza resultados parciales de una investigación en curso y registros del eje Educación Básica del Plan Estatal de Educación en Derechos Humanos - SP. La investigación sugiere más inversiones de las instituciones públicas y privadas y en formaciones que promuevan la reflexión y el ejercicio de construir relaciones humanas, asumiendo una postura ética ante de la vida social, cultural y política a nivel individual, colectivo y organizacional. Destaca la escuela como local de estructuración de conciencia social y de constitución de sujetos comprometidos con la promoción de derechos.

Palabras clave: Educación en Derechos Humanos. Justicia Curricular. Violencia contra el niño. Escuela en la prevención de la violencia.

\section{NOTAS}

1 Dados do PNAD 2015.

2 Estudos realizados de 2007 a 2017, publicados em periódicos revisados por pares, disponíveis no portal de periódicos da CAPES. 


\section{REFERÊNCIAS}

ALBUQUERQUE, L.M et al.. Terminologia da enfermagem caracterizadora da violência doméstica contra crianças e adolescentes. Revista Brasileira de Enfermagem, v.68, n. 3, p.452-459, jun. 2015.

ANDRADE, F.C.B, Violência. In: STRECK, D.; REDIN, E.; ZITKOSKY, J. (Orgs.). Dicionário Paulo Freire. Belo Horizonte: Autêntica Editora, 2010. p.109-110.

BENEVIDES, M. V.. Prefácio. In: SCHILLING, Flávia (Org.). Direitos humanos e educação: outras palavras, outras práticas. São Paulo: Cortez, 2005.

BÉRGAMO, L. P. D; BAZON, M. R. Experiências infantis e risco de abuso físico: mecanismos envolvidos na repetição da violência. Psicologia: Reflexão e Crítica, Porto Alegre, v. 24, n.4, 2011. Disponível em: < http://www.scielo.br/scielo.php?script=sci_ arttext\&pid=S0102-7972 2011000 400011> Acesso em: out. 2017.

BRASIL. Comitê Nacional de Educação em Direitos Humanos. Plano Nacional de Educação em Direitos Humanos. Brasília: Secretaria Especial dos Direitos Humanos; Ministério da Educação; Ministério da Justiça; UNESCO, 2009.

Lei 9394/96 - Lei de Diretrizes e Bases da Educação Nacional. Disponível em <www.planalto.gov.br >. Acesso em: out. 2017.

. Secretaria de Direitos Humanos. Plano Nacional de Enfrentamento à Violência Sexual contra Crianças e Adolescentes, 2013. Disponível em: <http://www.sdh.gov.br/ assuntos/bibliotecavirtual/criancas-e-adolescentes/publicacoes-2013/pdfs/plano-nacional-de-enfrentamento-da-violencia-sexual-contra-crianca-e-adolescentes $>$. Acesso em: dia out 2017.

BUENO, F. B. A política de assistência social desenvolvida nos CRAS de Sertãozinho para a prevenção da violência doméstica contra crianças e adolescentes. 2015. 107 f. Dissertação (Mestrado) - Universidade Estadual Paulista Júlio de Mesquita Filho, Faculdade de Ciências Humanas e Sociais, 2015. Disponível em: <http://hdl.handle. net/11449/127759>. Acesso em: dia out. 2017.

CANDAU, V. M. Educação em Direitos Humanos: uma proposta de trabalho. Novamérica, PUC-RJ, 1998. (Mimeo.).

CHAUÍ, M. Ética, violência e política. In: Cultura e democracia. O discurso competente e outras falas. 11. ed. São Paulo: Cortez, 2006.

DE OLIVEIRA, S. M. et al. Reporting of violence against children and adolescents: action of nurses in basic health units. UERJ Nursing Journal, Rio de Janeiro, v. 21, n. 5, 2013. Disponível em: <http://www.e-publicacoes.uerj.br/index.php/enfermagemuerj/ article/view/ 10012/8064. Acesso em: out. 2017.

DESLANDES, S.F.et al.. Uso da Técnica Grupo Nominal e do Método Delphi para a elaboração de indicadores de avaliação das estratégias de enfrentamento da violência contra crianças e adolescentes no Brasil. Revista Brasileira de Saúde Materno Infantil, 
v. 10, p. 29-37, 2010. Disponível em: < http://www.scielo.br/scielo.php?pid=S1519-38292010000500003\&script=sci_abstract\&tlng=pt> Acesso em: out 2017.

FONSECA, R.M.G.S et al. Reincidência da violência contra crianças no município de Curitiba: um olhar de gênero. Acta Paulista de Enfermagem, São Paulo, v. 25, n.6, p. 895-901, 2012. Disponível em: <http://www.scielo.br/scielo.php?script=sci_arttext\& pid=S0103-21002012000600011> Acesso em: dia out. 2017.

FREIRE, P. Educação e mudança. 10. ed. Rio de Janeiro: Paz e Terra, 1983.

. Educação na cidade. 5. ed. São Paulo: Cortez, 2001.

.Pedagogia do oprimido. 37. ed. Rio de Janeiro: Paz e Terra, 2003.

GADOTTI, M. Trabalho e educação numa perspectiva emancipatória. In: FÓRUM MUNDIAL DE EDUCAÇÃO PROFISSIONAL ETECNOLÓGICA-DEMOCRATIZAÇÃO, EMANCIPAÇÃO E SUSTENTABILIDADE, 2., 2012, Florianópolis. Anais... Florianópolis: 2012.

GUERRA, V. N. de A. Violência de pais contra filhos: a tragédia revisitada. 3. ed. São Paulo: Cortez, 1998.

ORGANIZAÇÃO DAS NAÇÕES UNIDAS (ONU). Diretrizes para a formulação de planos nacionais de ação para educação em direitos humanos. Quinquagésima Segunda Sessão da Assembleia Geral, 20 de outubro de 1997.

PONCE, B.J.; NERI, J.F.O. O currículo escolar em busca da justiça social: a violência doméstica contra a criança e o adolescente. Revista e-Curriculum, PUC-SP, São Paulo, v. 13, n. 2, p. 331- 349, abr./jun. 2015.

. A justiça curricular e a violência sexual intrafamiliar (VSI) como obstáculo ao direito ao conhecimento. Revista e-Curriculum, PUC-SP, São Paulo, v.15, n. 4, p. 12081233, out./dez. 2017.

SÃO PAULO. (Estado). Comitê Estadual de Educação em Direitos Humanos. Plano Estadual de Educação em Direitos Humanos. São Paulo, 2017. (No prelo).

SAUL, A.M. Currículo. In: STRECK, D.; REDIN, E.; ZITKOSKY, J. (Org.). Dicionário Paulo Freire. Belo Horizonte: Autêntica Editora, 2010. p.109-110.

SILVA, A.M. Direitos humanos na Educação Básica: qual significado? In: SILVA, A.M., TAVARES, C. (Org.). Políticas e fundamentos da Educação em Direitos Humanos. São Paulo: Cortez, 2010. p. $41-63$

SOUZA, R.F; OLIVEIRA, T.F. A doxa e o logos na educação: o avanço do irracionalismo. In: FRIGOTTO, G.(Org.). Escola "sem" partido: esfinge que ameaça a educação e a sociedade brasileira. Rio de Janeiro: UERJ; LPP, 2017.

TORRES SANTOMÉ, J. Currículo escolar e justiça social: o cavalo de Tróia da educação. Porto Alegre: Penso, 2013.

ZANATTA, C.T; DELL'AGLIO, D.D; CASTELLÁ, J.S. Direitos da criança e do adolescente e maus tratos: epidemiologia e notificação. Revista da SPAGESP, v. 17, n.1, p. 14-27, 2016. 
ZENAIDE, M. N.T.; CARNEIRO, G. Representações sociais da prática institucional e direitos humanos e educação popular em João Pessoa. João Pessoa: UFPB, 1994. (Mimeo.).

ZITKOSKI, J. J. Ser mais. In: STRECK, D.; REDIN, E.; ZITKOSKY, J. (Org.). Dicionário Paulo Freire. Belo Horizonte: Autêntica Editora, 2010. p. 369-371.

Branca Jurema Ponce: Professora titular da Pontifícia Universidade Católica de São Paulo (PUC-SP). Atua na Linha de Pesquisa de Políticas Públicas e Reformas Educacionais e Curriculares do Programa de Estudos Pós-Graduados em Educação: Currículo. Líder do Grupo de Educação e Pesquisa em Justiça Curricular (GEPEJUC) do CNPq. Bolsista na modalidade produtividade em pesquisa (PQ) do CNPq.

E-mail: tresponces@uol.com.br

Juliana Fonseca de Oliveira Neri: Doutora em Educação pela Pontifícia Universidade Católica de São Paulo (PUC-SP), na Linha de Pesquisa de Políticas Públicas e Reformas Educacionais e Curriculares. Atualmente é membro do Grupo de Educação e Pesquisa em Justiça Curricular (GEPEJUC) do CNPq e professora do curso de Pedagogia da Universidade Metropolitana de Santos (UNIMES).

E-mail: julianafoneri@gmail.com 